\title{
PERBEDAAN SOCIAL LOAFING DITINJAU DARI JENIS KELAMIN DAN LAMA KERJA PADA KARYAWAN UD JIBAY MELATI TEGAL
}

\author{
DIFFERENCES IN SOCIAL LOAFING REVIEWING FROM GENDER AND LONG \\ WORKING AT UD JIBAY EMPLOYEES MELATI TEGAL
}

\section{Oleh : \\ Fariz Amanuloh ${ }^{1}$ \\ Suwarti ${ }^{2}$}

\begin{abstract}
ABSTRAK
Penelitian ini bertujuan untuk mengkaji perbedaan social loafing ditinjau dari jenis kelamin dan lama kerja pada karyawan UD. Jibay Melati di Tegal. Hipotesis yang diajukan adalah perbedaan social loafing yang ditinjau dari jenis kelamin dan lama kerja pada karyawan UD Jibay Melati, Tegal. Variabel yang digunakan dalam penelitian ini adalah Social Loafing. Penelitian ini merupakan penelitian kuantitatif dimana instrumen yang digunakan untuk mengumpulkan data yaitu skala social loafing sejumlah 36 aitem, dengan subjek sebanyak 50 karyawan. Skala Social Loafing memiliki validitas yang bergerak dari 0,307-0,602. Koefisien reliabilitas dengan menggunakan Alpha Cronbach sebesar 0,776. Teknik analisis data yang digunakan yaitu Uji beda. Hasil analisis data menunjukkan nilai $\mathrm{t}=-0,633$ dan $\mathrm{p}=0,530>0,005$ pada jenis kelamin dan $\mathrm{t}=-0.033$ dan $\mathrm{p}=0,974$ pada lama kerja. Dari hasil analisis tersebut disimpulkan bahwa tidak ada perbedaan yang signifikan social loafing dari jenis kelamin (baik laki-laki maupun perempuan); serta tidak ada perbedaan dari lama kerja (baik yang bekerja kurang dari 6 tahun dan lebih dari 6 tahun).
\end{abstract}

Kata Kunci : Social Loafing, Jenis kelamin, Karyawan, Lama kerja

\begin{abstract}
This study aims to examine the differences in social loafing in terms of gender and length of work of employees in UD Jibay Melati, Tegal. The hypothesis proposed is the difference in social loafing in terms of gender and length of work of employees in UD Jibay Melati, Tegal. The variable used in this research is social loafing. This study is a quantitative study where the instrument used to collect data is a social loafing scale of 36 items, with a subject of 50 employees. The social loafing scale has a validity ranging from 0.30 to 0.602 . The reliability coefficient using Cronbach's Alpha is 0.776 . The data analysis technique used is the different test. The results of data analysis showed the value of $t$ test $=-0.633$ and $p=0.530>0.005$ for gender and t test $=-0.033$ and $\mathrm{p}=0.974$ for length of work. From the results of the analysis it was concluded that there was no significant difference in social loafing by gender (both male and female); and there is no difference in length of work (both those working less than 6 years and more than 6 years).

Keywords: Social Loafing, Gender, Employees, Length of work
\end{abstract}

${ }^{1}$ Fariz Amanuloh, Fakultas Psikologi, Universitas Muhammadiyah Purwokerto. fanjoe197@gmail.com

${ }^{2}$ Suwarti, Fakultas Psikologi, Universitas Muhammadiyah Purwokerto. suwartidarman@ gmail.com 
FARIZ AMANULOH \& SUWARTI

Perbedaan Social Loafing Ditinjau Dari Jenis Kelamin Dan Lama Kerja pada Karyawan UD Jibay Melati Tegal

\section{PENDAHULUAN}

Dunia bisnis saat ini telah berkembang dengan sangat pesat secara global sehingga mengakibatkan persaingan dalam dunia bisnis secara lebih kompetitif. Secara historis usaha kecil atau bisnis rumahan (home industry) memiliki peran yang cukup penting dalam pembangunan sebuah negara. Bisnis rumahan sendiri dapat membantu perkembangan perekonomian masyarakat yang tinggal di wilayah perusahaan, karena dari bisnis rumahan itu sendiri dapat membantu untuk membuka lapangan pekerjaan bagi masyarakat di sekitarnya sehingga bisa mengurangi jumlah pengangguran yang ada di sebuah negara dan berpengaruh pada sistem pasar nasional (Harymawan, et al. (2019).

Bisnis rumahan di Indonesia sendiri kebanyakan di pegang penuh atau di jalankan oleh sebuah keluarga seperti pada penelitian yang dilakukan oleh Claessens et al.(Hariyanto \& Juniarti, 2014) mendapati 68.6\% dan penelitian oleh ahmad, et al. Mendapati 61.7\% perusahaan di Indonesia dimiliki oleh keluarga. Selain itu Jakarta Consulting Group juga meneliti tentang kepemilikan keluarga yang diperoleh bahwa $82 \%$ di Indonesia adalah mayoritas perusahaan keluarga. Harymawan, et al. (2019) berpendapat bahwa perusahaan keluarga adalah sebuah perusahaan yang dimiliki, di kontrol, dan dijalankan oleh beberapa anggota keluarga.

Menurut Coopers (dalam Chan, 2019), bisnis keluarga di Indonesia mencapai persentase $95 \%$ dari total keseluruhan perusahaan yang ada. Didukung oleh pernyataan dari Indonesia Branding Forum bahwa partisipasi perusahaan keluarga pada ekonomi Indonesia secara langsung berkontribusi sebesar $25 \%$ pada PDB dalam negeri dalam research yang dilakukan oleh Pasopati \& Audriene, (2016).

Jibay Melati merupakan usaha dagang (UD) milik keluarga yang menyediakan bunga melati untuk penyetok dan pabrik teh serta mengolah sendiri bunga melati menjadi bahan pelengkap prosesi pernikahan. Bunga melati yang tersedia di perusahaan ini ada beberapa jenis bunga melati yaitu jenis bunga melati polos, melati gundul, melati sambac, melati multiflorum, melati offinale, melati rex dan melati bergius. Perusahaan jibay melati di kelola oleh sebuah keluarga dan dengan beberapa karyawan dari kerabat sang pemilik, seperti paman dari pemilik perusahaan, adik dari ibu pemilik perusahaan dan beberapa kerabat lainya. Perusahaan jibay sendiri sudah memasuki generasi ketiga setelah dipegang oleh Pak Wiryono ayah kandung Aji Bayu.

Organisasi atau perusahaan baik berskala besar maupun kecil haruslah memiliki kerjasama tim yang baik. Karena ketika antar individunya dapat bekerja dengan baik secara kelompok maka akan terwujud visi dan misi perusahaan yang sudah terancang. Perusahaan atau organisasi juga tidak luput dari permasalahan, terdapat fenomena ketika sekelompok orang mengerjakan sebuah kegiatan, terdapat satu atau lebih anggota yang sedikit atau sama sekali tidak memberikan kontribusi. Mereka hanya duduk-duduk, bersantai, melihat rekan-rekan yang lain bekerja, atau berusaha menghindar dengan bermacam alasan. Kemudian juga ada orang yang berperilaku tidak menolong, seperti saat dalam sebuah perkejaan ada rekan lain yang kesulitan dalam mengerjakan tugasnya. Namun, orang yang bersangkutan bersikap acuh karena beranggapan itu bukan tugasnya. Fenomena seperti inilah yang di sebut dengan social loafing atau kemalasan sosial. Social loafing dapat diartikan membiarkan orang lain melakukan pekerjaan saat menjadi bagian dari kelompok (Baron \& Byrne, 2004).

Duffy dan Shaw (Murphy, dkk., 2003) dalam penelitiannya menemukan bahwa social loafing secara negatif berhubungan dengan kohesivitas dan potensi kelompok, dimana, pada akhirnya, mengarah kepada rendahnya performansi, ketidakhadiran anggota kelompok, dan 
rendahnya kepuasan kelompok. Oleh karena itu, sangatlah penting untuk melakukan penelitian mengenai social loafing.

Bedasarkan hasil studi pendahuluan yang dilakukan dengan wawancara terhadap pemilik UD Jibay Melati mengatakan bahwa sering terjadi karyawan bersikap pasif, tidak punya tanggung jawab, kurang ada rasa menolong terhadap anggota lain, tidak asertif, dan tidak mau berusaha mengatasi masalah. Baik karyawan pria ataupun perempuan baik dari segi yang sudah lama bekerja maupun belum. Sebagian dari mereka memperlihatkan sikap yang disebutkan diatas selama bekerja sehingga muncul penurunan produktivitas.

Berdasarkan uaraian diatas, dapat disimpulkan munculnya social loafing pada karyawan UD Jibay Melati Tegal dapat dipengaruhi oleh jenis kelamin ataupun lama kerja karyawan. Oleh karena itu, peneliti tertarik untuk menguji bagiamana perbedaan jenis kelamin dan lama kerja dalam mempengaruhi social loafing pada karyawan UD Jibay Melati Tegal dengan melakukan penelitian berjudul : "Perbedaan Social Loafing Di Tinjau dari Jenis Kelamin dan Lama Kerja Pada Karyawan UD Jibay Melati, Tegal”.

\section{METODE PENELITIAN}

Penelitian ini dilakukan di UD Jibay Melati, desa Maribaya Kecamatan Keramat Kabupaten Tegal. Variabel yang digunakan dalam penelitian ini adalah Social Loafing. Populasi dalam penelitian ini adalah semua karyawan di UD Jibay Melati yang berjumlah 50 karyawan. Jumlah sampel pada penelitian ini sama dengan jumlah populasi, diperoleh dengan menggunakan teknik pengambilan sampel secara sengaja dimana sampel diambil tidak menggunakan kriteria tertentu.

Pada penelitian ini, peneliti menggunakan try out terpakai dikarenakan kesulitan melakukan pengambilan data ditengah keadaan pandemi covid-19. Metode pengumpulan data yang digunakan dalam penelitian ini yaitu skala social loafing yang dibuat sendiri oleh peneliti. Skala ini mengacu pada indikator social loafing yang dikemukakan oleh George (1992) yang meliputi : (1). Adanya pengurangan usaha saat bekerja dengan anggota kelompok yang lain; (2). Kurang bertanggung jawab terhadap tugas kelompok. (3). Mengandalkan orang lain.

Skala Social Loafing berjumlah 36 aitem. Skala Social Loafing memiliki validitas yang bergerak dari 0,307-0,602. Koefisien reliabilitas dengan menggunakan Alpha Cronbach sebesar 0,776. Penelitian ini bertujuan untuk mengkaji perbedaan jenis kelamin dan lama kerja pada skala social loafing, oleh karena itu metode analisis yang digunakan dalam penelitian ini adalah teknik Uji t sampel independen.

\section{HASIL}

Berdasarkan hasil uji beda di ketahui jumlah laki-laki sebanyak= 27 karyawan, untuk perempuan ada 23 karyawan. Nilai rata-rata untuk karyawan yang melakukan social loafing adalah laki-laki sebesar 105,78 sedangkan perempuan sebesar 104,26. Dengan demikian secara deskriptif statistic dapat disimpulkan tidak ada perbedaan rata-rata hasil karyawan yang melakukan social loafing antara laki-laki dengan perempuan. Berdasarkan hasil uji beda untuk Perbedan social loafing pada Laki-laki dan perempuan diperoleh hasil sebagai berikut ttest $=-0,633$ dan $\mathrm{p}=0,530(>0,05)$ dari hasil tersebut dapat disimpulkan bahwa tidak ada perbedaan yang signifikan social loafing antara karyawan laki-laki dan perempuan.

Pada lama kerja di peroleh data karyawan yang bekerja kurang dari 6 tahun sebanyak 22 karyawan dengan nilai rata-rata 105,04. Sementara yang bekerja lebih dari 6 tahun sebanyak 28 karyawan dengan nilai rata-rata 105,12. Dengan demikian secara deskriptif statistik dapat disimpulkan tidak ada perbedaa rata-rata hasil karyawan yang melakukan social 
FARIZ AMANULOH \& SUWARTI Perbedaan Social Loafing Ditinjau Dari Jenis Kelamin Dan Lama Kerja pada Karyawan UD Jibay Melati Tegal

loafing antara yang bekerja kurang dari 6 tahun dengan yang lebih dari 6 tahun. Berdasarkan hasil uji beda untuk Perbedan social loafing pada lama kerja kurang dari 6 tahun dan lebih dari 6 tahun diperoleh hasil t-test $=-0,033$ dan $\mathrm{p}=0,974(>0,05)$ dari hasil tersebut dapat dismpulkan bahwa tidak ada perbedaan yang signifikan social loafing antara karyawan yangbekerja selama kurang dari 6 tahun dan karyawan yang bekerja lebih dari 6 tahun.

\section{PEMBAHASAN}

Hasil penelitian ini memperkuat penjelasan dari George (1992) menyebutkan bahwa social loafing merupakan kondisi dimana individu hanya melakukan sedikit usaha untuk menyelesaikan tugas kelompok saat ada anggota kelompok yang lain melakukan tugas tersebut. Social loafing terjadi karena individu berpikir bahwa usaha mereka tidak begitu dibutuhkan karena usaha mereka bisa dilakukan (dipenuhi) oleh orang lain. Merujuk pada konsep George (1992) tersebut, diperoleh diperoleh tiga indikator social loafing sebagai berikut. 1. Adanya pengurangan usaha saat bekerja dengan anggota kelompok yang lain. 2 . Kurang bertanggung jawab terhadap tugas kelompok. Seseorang tidak mau terlibat banyak dalam suatu kelompok dan hanya sedikit kemampuan yang dikeluarkan (Kunishima, 2004). 3. Mengandalkan orang lain. Seseorang tidak mau terlibat banyak dalam mengerjakan tugas kelompok dengan menaruh kesanggupan pengerjaan tugas kelompok kepada anggota kelompok yang lain.

Social loafing adalah kecenderungan individu untuk memberikan usaha yang lebih sedikit ketika dalam kelompok dibandingkan jika ketika bekerja sendirian. Social loafing diketahui semakin terjadi seiring dengan bertambahnya ukuran kelompok, jika ditotalkan, hasil yang diperoleh dari kerja kelompok justru lebih rendah dari total hasil pekerjaan secara individual. Akibatnya, alih-laih mendapatkan hasil kolaboratif yang lebih baik, kelompok malah memberikan outcome yang tidak optimal bagi sebuah organisasi atau kelompok (Aminah, 2017).

Dari hasil uji beda juga dari jenis kelamin mendapatkan hasil $\mathrm{t}=-0,633$ dan $\mathrm{p}=0,530$ sedangkan lama kerja mendapatkan hasil $\mathrm{t}=-0,033$ dan $\mathrm{p}=0,974$ dari hasil tersebut dapat dismpulkan bahwa tidak ada perbedaan yang signifikan antara jenis kelamin laki-laki dan perempuan serta lama kerja yang kurang dari 6 tahun dan lebih dari 6 tahun.

Social loafing dapat terjadi pada laki-laki maupun perempuan serta pada anak-anak maupun orang dewasa. Satu-satunya faktor pengecualian pada generalitas social loafing adalah budaya. Social loafing tidak tampak terjadi dalam budaya kolektivitas, seperti terdapat di banyak negara Asia, budaya yang lebih menghargai kebaikan-kebaikan kolektif daripada prestasi individual. Orang-orang terlihat bekerja lebih keras saat berada dalam kelompok daripada saat bekerja mandiri dalam budaya seperti ini (Baron dan Byrne, 2004).

Hasil penelitian Aulia dan Saloom (2013) mendukung penelitian ini, dimana Aulia dan Saloom menyatakan bahwa jenis kelamin tidak mempengaruhi terjadinya social loafing. Artinya, baik laki-laki maupun perempuan kemungkinan melakukan social loafing sama besarnya. Penelitian senada dilakukan oleh Smarr (in press) yang menyatakan bahwa tidak adanya pengaruh perbedaan jenis kelamin terhadap terjadinya social loafing. Hal ini dimungkinkan terjadi karena kedekatan antar anggota yang sangat baik, kelompok yang sangat kohesif ataupun karena berada dikelompok yang kecil. Kedekatan dan kohesivitas laki-laki dan perempuan tidak menunjukan perbedaan terhadap kemungkinan untuk melakukan social loafing, sehingga peluangnya sama besar antara laki-laki dan perempuan

Berdasarkan penelitian yang dilakukan oleh Pratama dan Wulanyani (2018) 
menyatakan bahwa tidak adanya pengaruh dari jenis kelamin terhadap kecenderungan social loafing dalam sebuah kelompok. Hal ini sejalan dengan penelitian Schindler \& Reese (2017)yang menyatakan bahwa kelompok yang terdiri dari laki-laki dan perempuan lebih jarang menunjukkan social loafing.

\section{KESIMPULAN DAN SARAN}

Kesimpulan dari penelitian ini bahwa : tidak ada perbedaan social loafing tinjau dari jenis kelamin dan lama kerja. Berdasarkan hasil penghitungan t-test diperoleh bahwa tidak ada perbedaan yang signifikan pada karyawan yang melakukan social loafing baik ditinjau dari jenis kelamin maupun lama kerja karyawan di UD Jibay Melati.

Saran yang dapat diberikan bagi perusahaan diharapkan agar membantu dan menunjang kegiatan-kegiatan yang bermanfaat untuk karyawan agar tingkat social loafing mereka rendah dengan cara seperti membuat kegiatan yang memotivasi mereka dalam bekerja keras. Bagi karyawan, diharapkan dapat sebagai acuan dalam memotivasi diri sendiri dan menetapkan target pribadi dalam bekerja sehingga terhindar dari kemalasan. Bagi peneliti selanjutnya diharapkan agar dapat meneliti social loafing berdasarkan faktor lain seperti harga diri, kohesivitas, efikasi diri dan komunikasi interpersonal.

\section{DAFTAR PUSTAKA}

Aminah, S. (2017). Fenomena Social Loafing Dalam Program Pemberdayaan Masyarakat Di Desa Binaan PMI (Studi Fenomenologi Dalam Praktek Pengembangan Masyarakat). Jurnal Pemberdayaan Masyarakat: Media Pemikiran dan Dakwah Pembangunan.; Vol. 1, no. 1 (2017), hal. 123-138. Yogyakarta : e-Jurnal UIN Suka.

Aulia, H., \& Saloom, G. (2013). Pengaruh Kohesivitas Kelompok dan Self Efficacy Terhadap Social Loafing pada Anggota Organisasi Kedaerahan di Lingkungan Uin Syarif Hidayatullah Jakarta. TAZKIYA Journal of Psychology, 1(1).

Baron, R.A. \& Byrne, D. 2004. Psikologi Sosial, Edisi X. Terjemahan oleh Ratna D., Melanie M.P., Dyah Y., dan Lita P.L., Jakarta : Erlangga.

Chan, H. C. (2019). Manajemen Konflik Dalam Perencanaan Suksesi Pada Perusahaan Keluarga PT Mitra Indonesia, 7(1).

George, J. M. (1992). Extrinsic and Intrinsic Origins of Perceived Social Loafing in Organizations. The Academy of Management Journal, 35(1), 191-202.

Hariyanto, L; dan Juniarti. 2014. Pengaruh Family control, Firm risk, Frm size, dan Firm age terhadap Profitabilitas dan Nilai perusahaan. Business Accounting Review. V.2, No. 1.

Harymawan, I; Nasih, M; Madyan,M; Sucahyati, D. 2019. The Role of Political Connections on Family Firm's Performance : Eviden from Indonesia. International Journal of Financial Studies. 7, 55. https://doi.org/10.3390/ijfs7040055

Karau, S.J., \& Williams, K.D. 1993. Social Loafing: A Meta Analytic Review and Theoretical integration. Journal of Personality and Social Psychology, 65 (4), 681-706.

Murphy, S.M., et.al. 2003. Understanding social loafing: The role of justice perceptions and exchange relationships. Journal of Human Relations, 56(1): 61-84.

Pratama, P. Y. S., \& Wulanyani, N. M. S. (2018). Pengaruh Kuantitas, Kemampuan Komunikasi Interpersonal, Dan Perilaku Altruisme Anggota Kelompok Terhadap Social Loafing Dalam Proses Diskusi Kelompok Di Fakultas Kedokteran Universitas Udayana. Jurnal Psikologi Udayana, 5(01), 197.

Schindler, S., \& Reese, G. (2017). Social Loafing in the Refugee Crisis : Information about 
FARIZ AMANULOH \& SUWARTI Perbedaan Social Loafing Ditinjau Dari Jenis Kelamin Dan Lama Kerja pada Karyawan UD Jibay Melati Tegal Existing Initiatives Decreases Willingness to Help. Societies, 7(13), 5-10. https://doi.org/10.3390/soc7020013 